\title{
EFEITO DE ÉPOCAS DE SEMEADURA E DENSIDADES DE PLANTAS SOBRE O RENDIMENTO DE CULTIVARES DE SOJA NO ESTADO DE SÃO PAULO
}

\author{
Clovis Pereira Peixoto ${ }^{1}$ \\ Gil Miguel de Sousa Câmara² \\ Mônica Cagnin Martins ${ }^{3}$ \\ Luis Fernando Sanglade Marchiori ${ }^{4}$
}

\section{RESUMO}

A soja (Glycine max (L.) Merrill), devido a sua multiplicidade de aplicações, quer na alimentação humana ou animal, em função do seu potencial produtivo, composição química e valor nutritivo, ocupa posição de destaque na economia brasileira, justificando a necessidade de pesquisas no sentido de otimizar o seu cultivo e reduzir os riscos de prejuízos. A área cultivada vem aumentando significativamente, gerando a necessidade de desenvolver novas tecnologias que permitam a exploração do potencial de cada cultivar para as diferentes regiões de cultivo. Assim, avaliou-se o desempenho vegetativo e o rendimento de três cultivares de soja, pertencentes a diferentes ciclos de maturação, instalados em épocas de semeadura normal, tardia e safrinha. Cada época constituiu experimento individual delineado em blocos casualizados num fatorial 3 x 3 (três cultivares: IAC-12, IAC-17 e IAC-19; três densidades de plantas: 10,20 e 30 plantas $\mathrm{m}^{-1}$ ), com três repetições. As características agronômicas (altura final de planta, número final de nós e número de ramificações na haste principal) e os componentes da produção da planta destinados à avaliação do rendimento (número total de vagens e o número

\footnotetext{
'Dep. de Fitotecnia da Escola de Agronomia da UFBA (AGRUFBA), C.P. 82, CEP: 44380-000 - Cruz das Almas, BA, Brasil. E-mail: cppeixot@ufba.br

${ }^{2}$ Dep. de Produção Vegetal da ESALQ/USP, C.P. 9, CEP: 13418-970 - Piracicaba, SP, Brasil.

${ }^{3}$ Pós-Graduanda do Departamento de Produção Vegetal - ESALQ/USP.

${ }^{4}$ Fazenda Areão - ESALQ/USP.
} 
total de grãos), foram determinados em 10 plantas aleatórias da parcela útil. A massa de 1000 grãos, bem como o rendimento de grãos, foram determinados com base na população final de plantas. Concluiu-se que;

a) as características agronômicas e os caracteres componentes do rendimento apresentam variações entre eles, com efeito de compensação, no sentido de uniformizar o rendimento de grãos, entre cultivares, densidades e época de semeadura; b) em época de semeadura safrinha, o cultivar IAC-19 apresenta maior rendimento de grãos, independentemente da densidade de plantas; c) a época de semeadura é a variável que mais influencia nas características agronômicas da planta e no rendimento de grãos.

Palavras-chave: Glycine max, características agronômicas, componentes de produção da planta, época de semeadura safrinha

\section{ABSTRACT}

\section{SOWING DATE AND PLANT DENSITIES ON THE YIELD SOYBEAN CULTIVARES IN THE STATE OF SÃO PAULO}

The soybean (Glycine max (L.) Merrill), due to its multiplicity of applications, its need for human or animal feeding, its high yield potential, chemical composition and nutritional value, occupies a top position in the Brazilian economy, which justifies the need for research to optimize the cultivation practices and reduce the risks of losses. The cultivated area is increasing significantly, generating the need to develop new technologies that allow the exploration of the potential of each cultivar for the different growing areas. Thus, the vegetative vigor and yield of three soybean cultivars of three different maturation dates, sowed on typical, late, and autumn sowing dates was evaluated. Three independent experiments, one for each sowing date, were carried out in a randomized block design, with a $3 \times 3$ factorial arrangement ( 3 cultivars: IAC-12, IAC-17 and IAC-19; three planting densities: 10, 20, and 30 plants $\mathrm{m}^{-1}$ ). The agronomic characteristics (final plant height, final number of nodes and number of branches) the production components and the yield (total number of pods and total number of grains), were determined for 10 random plants per plot. The weight of 1,000 grains and grain yield were 
determined having in view the final population of plants per plot. Results obtained indicated that: a) the agronomic characters and yield components showed variation among themselves, with a compensating effect among cultivars, densities, and sowing dates, providing a uniform grain yield; b) the cultivar IAC-19 gives the best grain yield performance in the autumn sowing date, independently of plant densities; c) the sowing date is the variable that affects mostly the agronomic characters and grain yield.

Key words: Glycine max, agronomic characters, yield components of plants, safrinha growing season.

\section{INTRODUÇÃO}

Dos mais de treze milhões de hectares ocupados pela cultura da soja no Brasil, metade localiza-se nos Estados do Paraná, Rio Grande do Sul, Santa Catarina e São Paulo. O restante situa-se em regiões de baixa latitude, distribuídos pelos Estados de MS, MT, GO, MG, BA, MA, PA e RO, ocupando os mais diferentes ambientes climáticos e edáficos (Câmara, 1998). Essa ocupação somente foi possível com base no desenvolvimento de cultivares de soja, adaptados a diferentes regiões (Sediyama, 1992; Câmara, 1998). Nesses trabalhos, buscam-se cultivares de soja com características agronômicas favoráveis, como alto rendimento, estabilidade da produção (rusticidade), porte ereto, altura de inserção da primeira vagem maior que $12 \mathrm{~cm}$, maturação uniforme, vagens indeiscentes, alta capacidade para fixação de $\mathrm{N}_{2}$, qualidade tecnológica do grão, q. dade fisiológica da semente, adaptação a baixas latitudes e período juvenil longo ou fase não-suscetível ao fotoperíodo. Estas características diferem entre os cultivares e são modificadas pelas condições ambientes, as quais variam entre locais, entre épocas e entre densidades de semeadura (Sediyama et al. 1992; Marchiori et al. 1999).

Existe grande variabilidade entre os cultivares com relação à sensibilidade a época de semeadura e a mudanças na região de cultivo (latitudes). Essa característica é muito importante nos casos em que o produtor necessite semear mais cedo ou mais tarde, da mesma forma que para novas regiões que irão iniciar o cultivo da soja. Em tais situações, ganha 
importância o caráter juvenilidade longa (Kiihl \& Garcia, 1989; e Toledo et al., 1994). Não menos importantes são os ensaios regionais de avaliação de cultivares de soja, principalmente quando realizados em diferentes épocas em uma mesma região (Câmara et al., 1998).

Provavelmente, nenhuma prática cultural isolada é mais importante para a soja do que a época de semeadura. A época de semeadura é definida por um conjunto de fatores ambientais que reagem entre si e interagem com a planta, promovendo variações no rendimento e afetando outras características agronômicas. As condições que mais afetam o desenvolvimento da soja são as que envolvem variações dos fatores meteorológicos: temperatura, umidade do solo e principalmente fotoperíodo.

Pesquisas realizadas no Brasil demonstram que a época de semeadura é a variável que produz maior impacto sobre o rendimento da cultura da soja. Para as condições brasileiras, a época de semeadura varia em função do cultivar, região de cultivo e condições ambientais do ano agrícola, geralmente apresentando uma faixa recomendável de outubro a dezembro. O mês de novembro, de maneira geral, tem proporcionado os melhores resultados de produtividade nos Estados em que a cultura é cultivada tradicionalmente (Rocha et al., 1984; Nakagawa et al., 1988; Embrapa, 1996).

A época de semeadura, além de afetar o rendimento, afeta também a arquitetura e o desenvolvimento da planta. Semeadura em época não adequada pode causar reduçṍes drásticas no rendimento, bem como dificultar a colheita mecânica, de tal modo que as perdas na colheita podem chegar a níveis elevados. Isto devido a alterações na altura das plantas, na altura de inserção das primeiras vagens, no número de ramificações, no diâmetro do caule e no acamamento. Estas características estão também relacionadas com a população e os cultivares e dependem das condições bioclimáticas, principalmente, fotoperíodo, temperatura e distribuição pluvial (Rocha et al., 1984; Nakagawa et al. 1988; Câmara, 1991; Garcia, 1992 e Peixoto, 1999).

Ao optar por uma determinada época de semeadura, o produtor está escolhendo uma certa combinação entre a fenologia da cultura e a 
distribuição dos elementos do clima na região de produção, que poderá resultar em elevado ou reduzido rendimento.

A época de semeadura denominada safrinha é uma opção normalmente realizada em sucessão à cultura da soja, em época normal, ou a outra cultura, semeada no início do período das chuvas. No Estado de São Paulo, a safrinha é instalada em fevereiro ou março de cada ano, após a colheita da cultura de verão. Embora não sejam encontradas muitas referências de natureza científica sobre o cultivo da soja em época safrinha, bem como não existam muitas informações sobre cultivares mais indicados para essas condições, uma vez que a seleção de cultivares em semeadura tardia é muito prejudicada por ataque de percevejo, a Embrapa (1996) indica que cultivares de ciclo de maturação médio e semitardios têm maiores potenciais de rendimento. Fato este comprovado por Marchiori et al. (1999) e Peixoto (1999), que, trabalhando com cultivares de ciclos de maturação precoce, semiprecoce e médio, em época safrinha, no Estado de São Paulo, concluíram que o cultivar IAC-19, de ciclo de maturação médio, apresentou o melhor desempenho e maior rendimento de grãos.

Estudos têm demonstrado que a melhor população de plantas para o sistema convencional de plantio da soja é de aproximadamente 400.000 plantas ha-1. Variações de $20 \%$ a $25 \%$ desse número, para mais ou para menos, não alteram significativamente o rendimento de grãos, na maioria dos casos, desde que as plantas sejam distribuídas uniformemente, sem muitas falhas. Entretanto, a melhor população depende da re $;$; ; época de semeadura e do cultivar (Embrapa, 1996).

A população é fator determinante para o arranjo das plantas de soja, uma vez que influencia o crescimento (Gaudêncio et al., 1990). Os mesmos autores, procurando definir a melhor população de plantas de soja na região Centro-Sul do Paraná, instalada em semeadura direta, observaram que a população de 280.000 plantas ha ${ }^{-1}$ não reduziu o rendimento da cultura, em comparação com a de até 650.000 plantas ha $^{-1}$, para os cultivares estudados, permitindo concluir que nas áreas onde o acamamento da soja é freqüente, populações de 280.000 a 350.000 plantas ha ${ }^{-1}$ podem ser utilizadas. 
A partir da década de 70 , o espaçamento recomendado para a cultura da soja varia de $0,40 \mathrm{~m}$ a $0,70 \mathrm{~m}$ entre as linhas, com densidades de 10 a 30 plantas por metro linear (Gaudêncio, 1990); atualmente há predominância de valores mais reduzidos, entre $0,40 \mathrm{~m}$ e $0,60 \mathrm{~m}$ (Embrapa, 1996), semeando-se número de sementes de modo a ter 16 plantas por metro linear, no espaçamento de $0,40 \mathrm{~m}, 20$ plantas no espaçamento de $0,50 \mathrm{~m}$ e 24 no espaçamento de $0,60 \mathrm{~m}$, para obter uma população de 400.000 plantas ha ${ }^{-1}$.

A soja tolera ampla variação na população de plantas, alterando mais a sua morfologia que o rendimento de grãos (Demuner, 1988; Gaudêncio et al., 1990). De modo geral, a maior resposta se verifica para a variação nos espaçamento entre fileiras de plantas, com tendência de maiores rendimentos nos menores espaçamentos (Garcia, 1992). A menor resposta da soja à população se deve à sua capacidade de compensação no uso do espaço entre plantas.

As características quantitativas como componentes do rendimento (número de vagens por planta, número de grãos por vagem e massa dos grãos), altura de planta, duração do ciclo e produtividade, são as mais importantes na escolha dos cultivares para cultivo e são as mais influenciadas pelo manejo.

Um dos componentes da planta que contribui para a maior tolerância à variação na população é o número de vagens por planta que varia inversamente ao aumento ou redução da população. Queiroz (1975), trabalhando com quatro cultivares de ciclos diferentes e populações de $10,30,50,70$ e 90 plantas por metro quadrado, obteve reduções no número de vagens por planta quando a população variou de 10 para 30 plantas por metro quadrado, tendo todos os cultivares reagido semelhantemente. O número de grãos por vagem, como era esperado, não apresentou variação para este efeito. Entretanto, as respostas da soja à variação no espaçamento e densidade de plantas não são, via de regra, consistentes, variando de ano para ano e em função de cultivares e das condições ambientais.

Neste trabalho objetivou-se avaliar o desempenho vegetativo e o rendimento de três cultivares de soja, pertencentes a diferentes ciclos de 
maturação, instalados em três épocas de semeadura no Estado de São Paulo e em três densidades de plantas, por meio de algumas características agronômicas e dos componentes da produção da planta.

\section{MATERIAL E MÉTODOS}

Os experimentos foram instalados em área experimental da Escola Superior de Agricultura Luiz de Queiroz, localizada na Fazenda Areão, no município de Piracicaba - SP, situando-se a $22^{\circ} 41^{\prime} 30^{\prime \prime}$ de latitude Sul, $47^{\circ} 38^{\prime} 30^{\prime \prime}$ de longitude Oeste e $546 \mathrm{~m}$ de altitude, em solo do tipo Podzólico Vermelho Escuro. O solo foi preparado de maneira convencional, a saturação de bases elevada a 70\% e o controle de plantas daninhas realizado com uso dos herbicidas trifluralina e imazaquim, nas doses de 2,0 $\mathrm{L} \mathrm{ha}^{-1}$ e 1,0 $\mathrm{L} \mathrm{ha}^{-1}$, respectivamente. A adubação foi fundamentada na análise química do solo e na expectativa de rendimento esperado da ordem de $2500 \mathrm{~kg}$ a $3000 \mathrm{~kg}$ de grãos ha-1. Utilizou-se o equivalente a 400 $\mathrm{kg} \mathrm{ha}^{-1} \mathrm{da}$ fórmula fertilizante $00-20-15$, proposta por Mascarenhas \& Tanaka (1996). Na semeadura, procedeu-se o tratamento químico das sementes com fungicida (Carboxim-20\% + Thiram-20\%, $280 \mathrm{~mL} 100$ $\mathrm{kg}^{-1}$ de sementes) e a inoculação das sementes com Bradyrhizobium japonicum.

Os cultivares IAC-17 (ciclo precoce), IAC-12 (ciclo semiprecoce) e IAC-19 (ciclo médio), foram semeados nas épocas de semeadura normal (12 de novembro), tardia (19 de dezembro) e safrinha (14 de março), para as condições do Estado de São Paulo.

Foram conduzidos três experimentos independentes, de maneira que, a cada época de semeadura correspondeu o delineamento experimental em 3 blocos casualizados em esquema fatorial $3 \times 3$ (três cultivares: IAC-12, IAC-17 e IAC-19; e três densidades de plantas: 10, 20 e 30 plantas $\mathrm{m}^{-1}$ ). Cada unidade experimental foi constituída por cinco linhas de $5,0 \mathrm{~m}$ de comprimento, no espaçamento de $0,50 \mathrm{~m}$ nas entrelinhas, sendo as duas linhas externas consideradas como bordaduras, obtendose as populações de 200,400 e 600 mil plantas ha ${ }^{-1}$.

Todos os dados coletados na área útil de cada repetição para as diferentes variáveis foram analisados estatisticamente, por meio da aná- 
lise da variância. Os efeitos estatisticamente significativos pelo teste $\mathrm{F}$ foram analisados pelo teste de Tukey, visando à comparação das médias entre os cultivares. Quando o objetivo foi estudar as diferentes densidades, utilizou-se a análise de regressão polinomial. Os dados de contagem, que não apresentaram distribuição normal ou variâncias heterogêneas foram transformados pela extração da raiz quadrada.

Para melhor compreensão e interpretação dos resultados relativos às características estudadas, coletaram-se os dados climáticos correspondentes aos valores médios mensais da temperatura do ar, da radiação solar total, do fotoperíodo e precipitação total mensal (Tabela 1) e acompanhou-se o desenvolvimento fenológico dos cultivares de soja em cada época de semeadura, seguindo-se a Escala Fenológica de Fehr \& Caviness (1977), adaptada por Câmara (1998), com ênfase na fase reprodutiva.

As determinações para avaliar os efeitos dos fatores épocas de semeadura, cultivares e densidades, sobre as características agronômicas (altura final de planta, número de nós e número de ramificações na haste principal) e sobre os componentes de produção da planta de soja (número total de vagens e número total de grãos), foram efetuadas em amostras aleatórias constituídas de 10 plantas por parcela útil, por ocasião da plena maturação da cultura. A massa de 1000 grãos, bem como o rendimento de grãos, foram determinados com base na população final de plantas existentes na área útil de cada parcela.

As plantas foram colhidas e após uma semana de armazenamento, em temperatura e umidade ambiente, o rendimento de grãos de cada repetição foi aferido e o valor obtido $\left(\mathrm{kg}\right.$ parcela $\left.\mathrm{a}^{-1}\right)$ transformado para rendimento $\left(\mathrm{kg} \mathrm{ha}^{-1}\right)$. Para determinar a umidade dos grãos produzidos, foi utilizado o Método da Estufa, a $105^{\circ} \pm 3^{\circ} \mathrm{C}$ por 24 horas, de acordo com as Regras de Análise de Sementes (BRASIL, 1992), procedendo-se posteriormente, à correção da umidade para 13\%.

\section{RESULTADOS E DISCUSSÃO}

Os valores médios mensais de temperatura, radiação solar, fotoperíodo e precipitação pluvial são apresentados na Tabela 1 e se refe- 
rem às principais condições climáticas pelas quais evoluíram os ciclos fenológicos dos cultivares em cada época de semeadura, nas condições do estado de São Paulo. Analisando-se as informações contidas nessa Tabela, nota-se que os valores médios de cada atributo climático pouco variaram da época de semeadura normal para a tardia, enquanto desta para a época de semeadura safrinha, diminuíram progressivamente. Entretanto, tais valores, segundo Ometto (1981), foram característicos dos meses em que durou a experimentação e encontram-se próximos das normais climatológicas da região.

Tabela 1. Valores médios de temperatura mensal $\left({ }^{\circ} \mathrm{C}\right)$ do ar e radiação solar(cal $\mathrm{cm}^{-2}$ ). Valores do fotoperíodo (h) correspondente ao $15^{\circ}$ dia de cada mês e valores totais de precipitação mensal $(\mathrm{mm})$.

\begin{tabular}{ccccc}
\hline Meses Ano & 'Temperatura & ${ }^{1}$ Radiação & ${ }^{2}$ Fotoperíodo & ${ }^{\text {lPecipitação }}$ \\
\hline Nov/96 & 22,9 & 451,1 & 13,2 & 198,7 \\
Dez/96 & 24,1 & 455,4 & 13,5 & 187,9 \\
Jan/97 & 23,7 & 396,8 & 13,4 & 343,7 \\
Fev/97 & 24,4 & 473,3 & 12,8 & 84,7 \\
Mar/97 & 23,7 & 380,5 & 12,2 & 73,1 \\
Abr/97 & 21,8 & 350,1 & 11,6 & 42,0 \\
Mai/97 & 18,8 & 299,4 & 11,1 & 51,6 \\
Jun/97 & 17,1 & 245,0 & 10,8 & 107,7 \\
Jul/97 & 18,1 & 299,8 & 10,9 & 19,3 \\
\hline
\end{tabular}

Fonte: ${ }^{1}$ Posto Meteorológico do Departamento de Física e Meteorologia da ESALQ/USP; ${ }^{2}$ Pereira et al. (1997).

Para a época de semeadura normal não foi verificada nenhuma restrição de clima para o pleno crescimento e rendimento da cultura. Para a semeadura em época tardia, registrou-se diminuição do fotoperíodo e da pluviosidade por ocasião do florescimento. Por outro lado, na época de semeadura safrinha, verificaram-se condições ambientais mais limitantes, com insuficiência térmica, fotoperiódica e, principalmente, pluvial, exigindo uma suplementação hídrica, através de irrigação. 
Para facilitar a análise comparativa entre as épocas de semeadura e os cultivares dentro e entre as épocas, elaborou-se a Tabela 2, onde se verifica redução na duração do subperíodo emergência - início do florescimento $\left(\mathrm{VE}-\mathrm{R}_{1}\right)$, da época de semeadura normal para a tardia, para os três cultivares de soja, devido à sensibilidade desta às variações na duração do fotoperíodo do ambiente, conforme já constatado por Rocha et al. (1984), Nakagawa et al. (1988), Marcos Filho \& Novembre (1990) e Câmara (1991). Entretanto, na época de semeadura safrinha, os cultivares alongaram a duração da fase vegetativa de seus respectivos ciclos fenológicos.

Tabela 2. Duração e dias dos principais estádios fenológicos dos cultivares de soja IAC-12, IAC-17 e IAC-19, semeados em época normal, tardia e safrinha.

\begin{tabular}{|c|c|c|c|c|c|c|c|c|c|}
\hline \multirow{2}{*}{$\mathrm{SF}^{\prime}$} & \multicolumn{3}{|c|}{ Normal } & \multicolumn{3}{|c|}{ Tardia } & \multicolumn{3}{|c|}{ Safrinha } \\
\hline & IAC -12 & IAC- 17 & IAC-19 & IAC-12 & IAC-17 & IAC-19 & IAC- 12 & IAC- 17 & IAC- 19 \\
\hline$S-V E$ & 8 & 8 & 8 & 8 & 8 & 8 & 8 & 8 & 8 \\
\hline$V E-R_{1}$ & 46 & 46 & 46 & 39 & 39 & 39 & 49 & 44 & 52 \\
\hline $\mathrm{R}_{1}-\mathrm{R}_{3}$ & 16 & 16 & 16 & 14 & 11 & 18 & 7 & 8 & 14 \\
\hline $\mathrm{R}_{3}-\mathrm{R}_{5}$ & 17 & 17 & 17 & 10 & 10 & 11 & 17 & 14 & 18 \\
\hline $\mathrm{R}_{5}-\mathrm{R}_{7}$ & 31 & 31 & 35 & 25 & 22 & 35 & 25 & 21 & 24 \\
\hline $\mathrm{R}_{7}-\mathrm{R}_{\mathrm{B}}$ & 16 & 15 & 24 & 15 & 10 & 18 & 14 & 11 & 14 \\
\hline$V E-R_{7}$ & 110 & 110 & 114 & 88 & 82 & 103 & 98 & 87 & 108 \\
\hline$V E-R_{8}$ & 126 & 125 & 138 & 103 & 92 & 121 & 112 & 98 & 122 \\
\hline$S-R_{8}$ & 134 & 133 & 146 & 111 & 100 & 129 & 120 & 106 & 130 \\
\hline
\end{tabular}

'Compreende os estádios VE a $\mathrm{R}_{8}$

Nota-se, ao contrário dos resultados encontrados por vários autores (Rocha et al., 1984; Nakagawa et al., 1988 e Câmara, 1991), que nessa época de semeadura, houve um encurtamento do ciclo na fase reprodutiva dos cultivares, no período relativo ao início do florescimento até a maturidade fisiológica. Observa-se ainda que esse encurtamento ocorreu de forma mais acentuada nos subperíodos fenológicos $R_{1}-R_{3} e$ 
$\mathrm{R}_{5}-\mathrm{R}_{7}$, mantendo-se praticamente igual durante o desenvolvimento dos legumes até o início de enchimento dos grãos $\left(R_{3} a R_{5}\right)$, voltando a reduzir moderadamente, no subperíodo $\mathrm{R}_{7}-\mathrm{R}_{8}$, em relação à época de semeadura normal.

Verifica-se que os cultivares IAC-12, IAC-19 e IAC-17 reduziram 14, 16 e 27 dias, respectivamente. Esses resultados concordam com obtidos por Marchiori et al. (1999) e Peixoto, (1999). Por outro lado, diversos autores obtiveram resultados contrários (Nakagawa et al. 1983; Rocha et al. 1984 e Câmara, 1991). O cultivar IAC-19 apresentou menor sensibilidade às condições ambientais, limitantes para a cultura da soja na época de semeadura safrinha, principalmente com relação a pluviosidade.

Pelo fato de as características agronômicas da soja apresentarem grande variabilidade entre os cultivares, em função das condições ambientes e da população de plantas, a que submetem seu cultivo, sugere-se estudar a associação entre os caracteres, sempre enfatizando a contribuição de cada um, para o rendimento em grãos. O rendimento da soja é uma característica complexa que pode ser decomposta em seus componentes: número de plantas por unidade de área, número de vagens por planta, número de grãos por vagem e massa de grãos.

Na Tabela 3 são apresentados os quadrados médios para as características altura final de planta, numero de nós, número de ramificações, número total de vagens por planta, número total de grãos por planta, massa de 1000 grãos e rendimento de grãos para os cultivares IAC-12, IAC-17 e IAC-19, nas épocas de semeadura normal, tardia e safrinha.

Com relação à altura final de planta a análise de variância revelou diferenças significativas nas três épocas de semeadura para os fatores cultivar e densidade, sem, contudo, apresentar significância para a interação entre eles, nas três épocas. Os resultados mostram que dentre os cultivares estudados (Tabela 4), o IAC-19, de ciclo de maturação médio, apresentou maior altura de planta, na época de semeadura normal e safrinha, diferindo estatisticamente dos demais, igualando-se ao IAC-17, na época de semeadura tardia, e significativamente superior ao IAC-12, mostrando que independente da densidade, foi o melhor para esse caráter. 


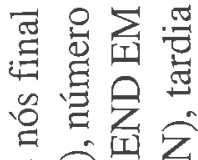

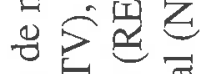

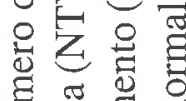

灵要

음 贾

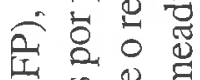

这常

赵

言

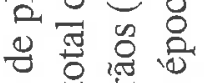

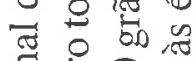

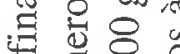

思

素完要

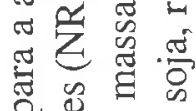

क.

尊它范

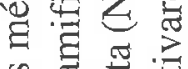

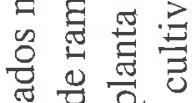

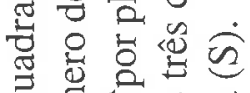

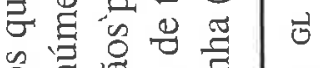

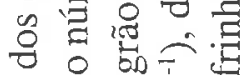

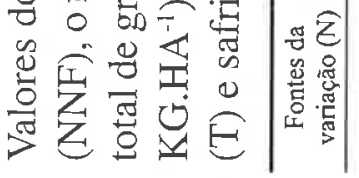

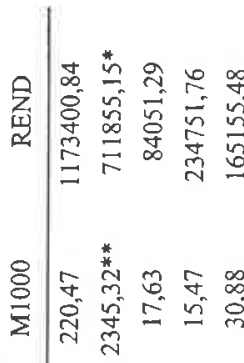

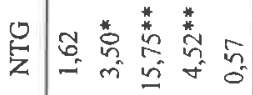

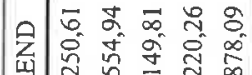

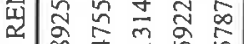

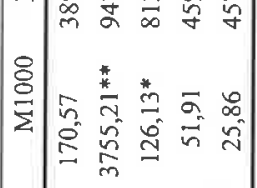

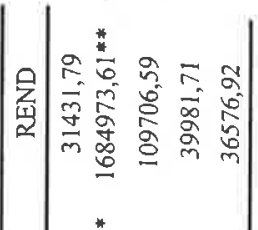

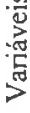

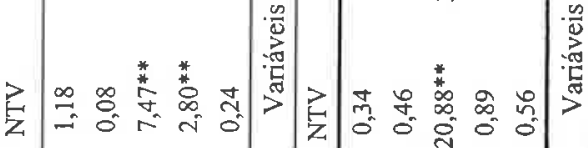

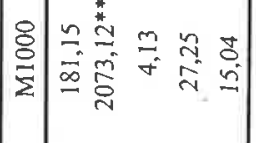

㫐

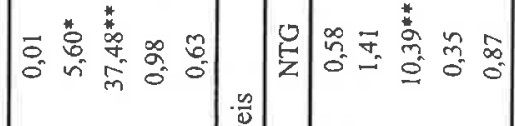

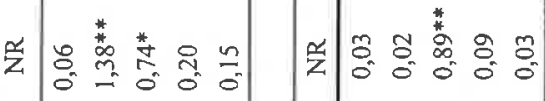

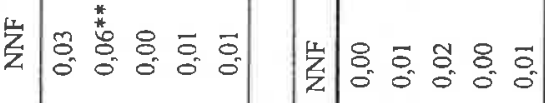

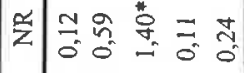

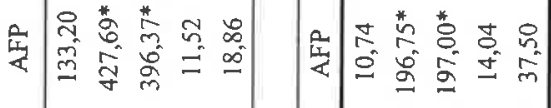

崖 $44 a+\frac{0}{4} 444 n+b$

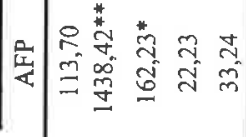

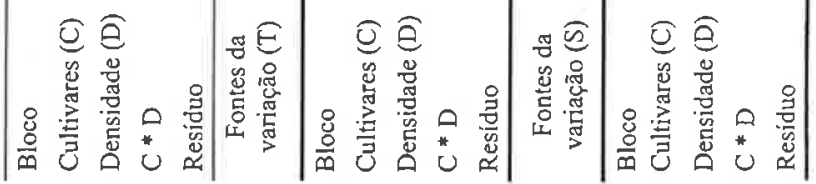

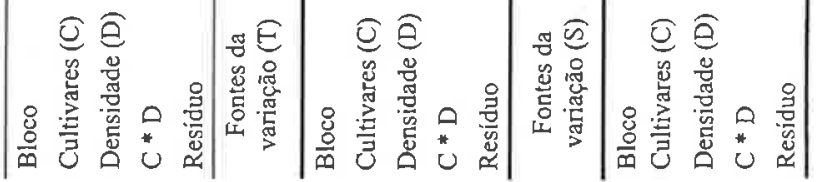

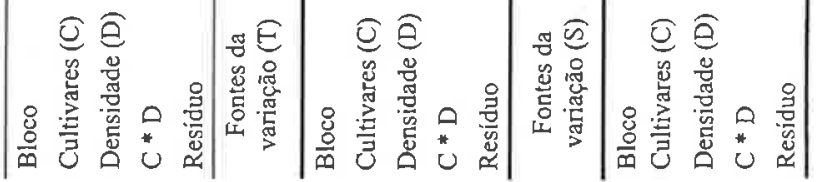

乑 
Observa-se que a altura final de planta diminui com o atraso na semeadura para todos os cultivares. No entanto, estes resultados contradizem Garcia (1992), que não verificou efeito de épocas de semeadura sobre a altura da plantas, para a maioria dos cultivares estudados. Por outro lado, Marchiori et al. (1999) afirmam que da época de semeadura normal para a época safrinha, houve redução no tamanho da planta de soja, devido à redução no comprimento do internódio e à formação de menor número de nós vegetativos na haste principal.

Vários autores verificaram redução na altura das plantas de soja, devido à menor duração do período vegetativo, relacionada a atrasos na semeadura (Marcos Filho, 1990; Sediyama et al., 1992 e Câmara, 1991). Entretanto, neste trabalho, observou-se um encurtamento do período reprodutivo, mais precisamente, nas fases compreendida entre o florescimento e a maturidade fisiológica, sendo que o IAC-17, de ciclo de maturação precoce, apresentou a maior redução (Tabela 2).

Com relação ao fator densidade, observou-se diferença significativa ao nível de $5 \%$ entre elas, com o teste $\mathrm{F}$ da análise de regressão polinomial, revelando valores altamente significativos para regressão quadrática na época de semeadura normal e regressões lineares, nas épocas de semeadura tardia e safrinha (Tabela 12). Verifica-se que, independentemente da época de semeadura, quanto maior a densidade de plantas na linha, maior é a altura final de planta, significando que na época de semeadura normal a densidade ótima estabiliza-se em torno de 20 plantas por metro. Nas épocas de semeadura tardia e safrinha, as regressões lineares indicam que entre 10 e 30 plantas por metro linear, cada unidade de planta aumenta em $0,5 \mathrm{~cm} \mathrm{e} 0,4 \mathrm{~cm}$, respectivamente, a altura da planta.

O número de nós vegetativos na haste principal de uma planta de soja está diretamente relacionado com a sua altura e a quantidade de pontos para inserção de vagens, que irão contribuir para o rendimento final de grãos. A análise de variância revelou que os cultivares diferiram significativamente ao nível de $1 \%$ de probabilidade, na primeira época, não houve diferenças na época de semeadura tardia, sendo, outra vez, altamente significativa ( $\mathrm{P}<0,01)$, na semeadura de época safrinha (Tabela 5). Entretanto, não se detectou efeito significativo para densidade, 
Tabela 4. Valores médios (cm) para altura final de plantas (AFP) observadas na época de semeadura normal, tardia e safrinha para os cultivares de soja IAC-12, IAC - 17 e IAC - 19, manejados sob três densidades de plantas.

\begin{tabular}{|c|c|c|c|c|c|}
\hline \multirow[t]{2}{*}{ Épocas } & \multirow[t]{2}{*}{ Cultivares } & \multicolumn{3}{|c|}{ Densidades (plantas $\mathrm{m}^{-1}$ ) } & \multirow{2}{*}{ Médias } \\
\hline & & 10 & 20 & 30 & \\
\hline \multirow{4}{*}{ Normal } & IAC -12 & 70,6 & 83,5 & 85,2 & $79,7^{1} b$ \\
\hline & IAC -17 & 70,0 & 80,9 & 76,5 & $75,8 \quad b$ \\
\hline & IAC - 19 & 81,2 & 91,8 & 94,6 & 89,1 a \\
\hline & \multicolumn{2}{|c|}{$\mathrm{DMS}=5,28$} & \multicolumn{2}{|c|}{$\mathrm{CV}=5,32 \%$} & \\
\hline \multirow{4}{*}{ Tardia } & IAC -12 & 52,6 & 58,3 & 62,1 & $57,7 \quad b$ \\
\hline & $\mathrm{IAC}-17$ & 63,0 & 66,2 & 69,0 & $66,0 \mathrm{a}$ \\
\hline & IAC -19 & 60,5 & 62,9 & 72,9 & $65,4 \mathrm{a}$ \\
\hline & \multicolumn{2}{|c|}{ DMS $=7,45$} & \multicolumn{2}{|c|}{$\mathrm{CV}=9,71 \%$} & \\
\hline \multirow{4}{*}{ Safrinha } & $\mathrm{IAC}-12$ & 34,2 & 43,2 & 48,0 & $41,5 \mathrm{~b}$ \\
\hline & IAC -17 & 35,5 & 38,4 & 39,9 & $36,0 \mathrm{~b}$ \\
\hline & $1 \mathrm{AC}-19$ & 58,6 & 60,0 & 65,9 & $61,5 \mathrm{a}$ \\
\hline & DMS & $=7,014$ & $\mathrm{CV}$ & $=12,24 \%$ & \\
\hline
\end{tabular}

'Médias seguidas por letras distintas, na coluna, diferem entre si pelo teste de Tukey a 0,05 de significância

em nenhuma época, indicando que o número de nós na haste principal, da planta de soja, não varia em função da densidade entre 10 e 30 plantas por metro de linha, nas três épocas estudadas.

Um outro aspecto a observar é que todos os cultivares reduziram o número de nós com o atraso na semeadura, sendo mais notório para o IAC-17, que apresentou maior sensibilidade à mudança de época, tanto nesta característica, quanto na altura final de plantas (Tabelas 4 e 5). O número de nós formados na haste principal da planta diminuiu da época de semeadura normal para safrinha, apresentando reduções de $21 \%, 27 \%$ e $15 \%$ para os cultivares IAC-12, IAC-17 e IAC-19, respectivamente, 
com o cultivar IAC-19 demonstrando ser menos sensível às influências de época, inclusive quanto ao caráter altura de planta, porquanto foi mais alto que os demais, nas épocas de semeadura normal e safrinha, sendo o único que apresentou altura compatível para alta produtividade, na ultima época (Sediyama et al., 1988; Garcia, 1992).

Tabela 5. Valores médios para número de nós observados nas épocas de semeadura normal, tardia e safrinha para os cultivares de soja IAC - 12, IAC - 17 e IAC -19, manejados com três densidades de plantas.

\begin{tabular}{|c|c|c|c|c|c|}
\hline \multirow{2}{*}{ Épocas } & \multirow{2}{*}{ Cultivares } & \multicolumn{3}{|c|}{ Densidades (plantas $\mathrm{m}^{-1}$ ) } & \multirow{2}{*}{ Médias } \\
\hline & & 10 & 20 & 30 & \\
\hline \multirow{4}{*}{ Normal } & IAC - 12 & $12,3^{2}$ & 12,3 & 13,0 & $12,6^{1}$ ab \\
\hline & $\mathrm{IAC}-17$ & 12,0 & 12,3 & 11,7 & $12,0 \quad \mathbf{b}$ \\
\hline & IAC - 19 & 13,0 & 13,0 & 13,3 & 13,1 a \\
\hline & DM & 10 & \multicolumn{2}{|c|}{$\mathrm{CV}=2,52 \%$} & \\
\hline \multirow{4}{*}{ Tardia } & $\mathrm{IAC}-12$ & 12,3 & 11,7 & 11,0 & 11,7 a \\
\hline & $\mathrm{IAC}-17$ & 11,7 & 11,3 & 11,0 & 11,3 a \\
\hline & IAC - 19 & 11,7 & 11,3 & 11,3 & $11,4 \mathrm{a}$ \\
\hline & \multicolumn{2}{|c|}{ DMS $=0,11$} & \multicolumn{2}{|c|}{$\mathrm{CV}=2,80 \%$} & \\
\hline \multirow{4}{*}{ Safrinha } & $\mathrm{IAC}-12$ & 10,0 & 10,3 & 9,3 & 9,9 b \\
\hline & IAC -17 & 9,3 & 8,7 & 8,3 & $8,9 \quad \mathrm{c}$ \\
\hline & IAC - 19 & 11,3 & 11,3 & 11,0 & 11,2 a \\
\hline & $\mathrm{DN}$ & 12 & \multicolumn{2}{|c|}{$C V=3,37 \%$} & \\
\hline
\end{tabular}

Médıas seguıdas por letras distıntas, na coluna, diterem entre sı pelo teste de 'lukey a 0,05 de significância.

${ }^{2}$ Dados $(\mathrm{x})$ transformados em $\sqrt{x}$.

Fazendo-se a relação entre altura final de planta e o número de nós vegetativos, obtém-se o comprimento médio de cada entrenó. Neste caso, observa-se que há um encurtamento da distância média entre os nós da haste principal, para todos os cultivares, principalmente para 
IAC-12 e IAC-17, que encurtaram cerca de dois centímetros da primeira para a terceira época de semeadura. Esta é uma característica bastante afetada pelas práticas de manejo quanto a populações de plantas e está também associada com a maior altura final de planta e ao número final de nós vegetativos na haste principal da planta de soja.

Os valores médios de ramificações de plantas observados nos cultivares de soja IAC-12, IAC-17 e IAC-19, manejados com três populações de plantas em três épocas de semeadura são apresentados na Tabela 6. Observam-se diferenças altamente significativas entre os cultivares, apenas para a época de semeadura normal. O teste de Tukey aponta para esta época, que o cultivar IAC-17 foi o que apresentou maior número de ramificações por planta, sendo significativamente superior aos outros dois cultivares. Por outro lado, embora os cultivares não tenham diferido significativamente nas semeaduras tardia e safrinha, o cultivar IAC - 17, nesta ultima, foi o que cresceu menos em altura, formou menor número de nós na haste principal e apresentou menor número de ramificações por planta.

Para o fator densidade, a análise de variância revelou efeito altamente significativo $(\mathrm{P}<0,01)$ para as primeiras épocas de semeadura e ao nível de $5 \%$ de probabilidade, para a época de semeadura safrinha (Tabela 3). A análise de regressão polinomial revelou, para as três épocas de semeadura, efeitos significativamente lineares e proporcionalmente inversos, significando que a cada aumento na densidade de plantas na linha, dentro do intervalo estudo, tem-se redução no número de ramificações por planta (Tabela 12). Esta redução no número de ramificações devido ao aumento na densidade está associada com a altura final de plantas e com o número de nós formados na haste principal, conforme descrito por Nakagawa et al. (1988), que obtiveram resultados semelhantes. Para Marchiori et al. (1998) e Peixoto (1999) que também estudaram essas associações, a densidade mostrou-se um fator útil para modificar a arquitetura da planta, permitindo adaptá-la a algumas condições especiais, particularmente à colheita mecanizada.

Os cultivares IAC-12, IAC-17 e IAC-19 não apresentam diferenças significativas para o número total de vagens nas três épocas de seme- 
Tabela 6. Valores médios para número de ramificações observadas nas épocas de semeadura normal, tardia e safrinha para os cultivares de soja IAC - 12, IAC - 17 e IAC - 19, manejados sob três densidades de plantas.

\begin{tabular}{|c|c|c|c|c|c|}
\hline \multirow{2}{*}{ Épocas } & \multirow{2}{*}{ Cultivares } & \multicolumn{3}{|c|}{ Densidades (plantas $\mathrm{m}^{-1}$ ) } & \multirow{2}{*}{ Médias } \\
\hline & & 10 & 20 & 30 & \\
\hline \multirow{4}{*}{ Normal } & $\mathrm{IAC}-12$ & $3,0^{2}$ & 1,0 & 0,4 & $1,3^{1} \quad b$ \\
\hline & IAC -17 & 5,0 & 3,3 & 2,8 & 3,7 a \\
\hline & IAC - 19 & 2,6 & 2,6 & 2,3 & $2,5 \mathrm{ab}$ \\
\hline & \multicolumn{2}{|c|}{ DMS $=0,47$} & \multicolumn{2}{|c|}{$\mathrm{CV}=25,42 \%$} & \\
\hline \multirow{4}{*}{ Tardia } & IAC -12 & 4,0 & 2,6 & 1,3 & $2,5 \mathrm{a}$ \\
\hline & IAC -17 & 3,7 & 2,3 & 2,3 & $2,7 \mathrm{a}$ \\
\hline & IAC - 19 & 3,7 & 3,3 & 1,6 & $2,8 \mathrm{a}$ \\
\hline & \multicolumn{2}{|c|}{ DMS $=0,21$} & \multicolumn{2}{|c|}{$C V=10,95 \%$} & \\
\hline \multirow{4}{*}{ Safrinha } & $\mathrm{IAC}-12$ & 2,3 & 1,6 & 1,3 & $1,7 \mathrm{a}$ \\
\hline & IAC -17 & 2,0 & 0,4 & 0,1 & $0,7 \mathrm{a}$ \\
\hline & IAC - 19 & 2,6 & 0,9 & 0,7 & $1,3 \mathrm{a}$ \\
\hline & \multicolumn{4}{|c|}{$C V=45,42 \%$} & \\
\hline
\end{tabular}

${ }^{1}$ Médias seguidas por letras distintas na coluna diferem entre si pelo teste de Tukey a 0,05 de significância.

${ }^{2} \operatorname{Dados}(\mathrm{x})$ transformados em $\sqrt{x}$.

adura. No entanto, tal característica foi altamente influenciada pela densidade nas três épocas e houve efeito significativo para a interação cultivar $\mathbf{x}$ densidade somente na semeadura normal (Tabela 3). O desdobramento das regressões para esse efeito é apresentado apenas para os cultivares IAC-12 e IAC-17, uma vez que a regressão polinomial para os níveis de densidade dentro do IAC-19 não foi significativa (Tabela 12). A equação mostra que para cada aumento no número de plantas na linha, dentro das densidades estudadas, obtém-se um decréscimo no número de vagens por planta. 
O número total de vagens diminuiu progressivamente da primei ra época para segunda e desta para a terceira, com a última apresentando reduções da ordem de $40 \%$ para o IAC-12, 39\% para o IAC-17 e $34 \%$ para o IAC-19. Estes dados indicam que o cultivar IAC-19, embora tenha apresentado menor número total de vagens nas três épocas, foi o menos sensível ao atraso da semeadura.

Sendo um dos componentes da produção da planta, o número total de vagens formadas por um cultivar deve estar associado a outras variáveis, como o número de grãos por vagem, pois há grande variação genotípica. O caráter número total de grãos, estreitamente relacionado com o número total de vagens, apresenta variação semelhante, de forma que também diminui com o aumento da população, como observado na Tabela 7, onde' a maioria dos resultados obtidos manteve a tendência relatada por Marchiori (1998).

A análise da variância para número total de grãos revelou diferenças significativas para os fatores cultivar e densidade e para a interação entre eles, na época normal, enquanto que na semeadura tardia, valores de $F$ significativos foram verificados apenas para os fatores cultivar e densidade. Na época de semeadura safrinha, houve diferenças estatísticas apenas para o fator densidade (Tabela 3). Para número total de grãos, o desdobramento da análise de regressão para a interação cultivar e densidade na época de semeadura normal revelou efeito quadrático para o cultivar IAC-12 e efeito linear para os cultivares IAC-17 e IAC-19 (Tabela 12).

Observa-se também que os valores do número total de grãos por planta foram sempre superiores na densidade 10 plantas $\mathrm{m}^{-1}$, destacando-se o cultivar IAC-12, nas épocas de semeadura normal e tardia (Tabela 8). Isto, provavelmente, é devido a melhor adaptação deste cultivar nas condições testadas. Na semeadura tardia, observa-se melhor desempenho do IAC-12, significativamente superior aos cultivares IAC-17 e IAC-19, que não diferiram entre si. Nesta época, também foi o cultivar IAC-12 quem mais produziu vagens por planta, embora não tenha diferido estatisticamente dos outros cultivares (Tabela 7). 
Tabela 7. Valores médios do número total de vagens por planta observados nas épocas de semeadura normal, tardia e safrinha para os cultivares de soja IAC-12, IAC-17 e IAC-19, em três densidades de plantas.

\begin{tabular}{|c|c|c|c|c|c|}
\hline \multirow{2}{*}{ Épocas } & \multirow{2}{*}{ Cultivares } & \multicolumn{3}{|c|}{ Densidades (plantas $\mathrm{m}^{-1}$ ) } & \multirow{2}{*}{ Médias } \\
\hline & & 10 & 20 & 30 & \\
\hline \multirow{4}{*}{ Normal } & IAC - 12 & $82,3^{1,2}$ a & $30,6 \quad b$ & 44,9 a & 49,2 \\
\hline & IAC -17 & 62,8 & $38,9 \quad b$ & $41,4 \mathrm{a}$ & 48,9 \\
\hline & $\mathrm{IAC}-19$ & $48,8 \quad \mathrm{~b}$ & 53,0 a & 40,3 a & 46,7 \\
\hline & \multicolumn{4}{|c|}{$\mathrm{DMS}=1,02$} & \\
\hline \multirow{4}{*}{ Tardia } & IAC - 12 & 77,6 & 42,0 & 25,8 & 46,1 a \\
\hline & $\mathrm{IAC}-17$ & 57,7 & 35,9 & 31,2 & 40,8 a \\
\hline & IAC - 19 & 63,5 & 44,4 & 21,4 & $41,2 \mathrm{a}$ \\
\hline & \multicolumn{4}{|c|}{$\mathrm{DMS}=0,91$} & \\
\hline \multirow{4}{*}{ Safrinha } & $\mathrm{IAC}-12$ & 24,1 & 20,4 & 14,0 & $19,6 \mathrm{a}$ \\
\hline & IAC -17 & 23,4 & 14,9 & 11,0 & 19,3 a \\
\hline & IAC - 19 & 27,7 & 17,8 & 14,0 & $16,0 \mathrm{a}$ \\
\hline & \multicolumn{4}{|c|}{$\mathrm{DMS}=0,80$} & \\
\hline
\end{tabular}

'Médias seguidas por letras distintas na coluna diferem entre si pelo teste de Tukey a 0,05 de significância

${ }^{2}$ Dados $(\mathrm{x})$ transformados em $\sqrt{x}$.

Verifica-se ainda que, em média, as produções de grãos nas épocas de semeadura normal e tardia foram semelhantes, com os cultivares produzindo cerca de duas vezes mais grãos em relação à época de semeadura safrinha. As menores diferenças entre as épocas de semeadura normal e safrinha foram obtidas pelo cultivar IAC-19, de ciclo de maturação médio, combinando com o maior número total de grãos por planta produzido nesta época.

Os dados médios para a massa de 1000 grãos observados nas épocas de semeadura normal, tardia e safrinha para os cultivares IAC-12, IAC-17 e IAC-19, estão apresentados na Tabela 9. A análise da variância 
Tabela 8. Valores médios do número total de grãos por planta observados nas épocas de semeadura normal, tardia e safrinha para os cultivares de soja IAC-12, IAC-17 e IAC-19, em três densidades de plantas.

\begin{tabular}{|c|c|c|c|c|c|}
\hline \multirow{2}{*}{ Épocas } & \multirow{2}{*}{ Cultivares } & \multicolumn{3}{|c|}{ Densidades (plantas $\mathrm{m}^{-1}$ ) } & \multirow{2}{*}{ Médias } \\
\hline & & 10 & 20 & 30 & \\
\hline \multirow{4}{*}{ Normal } & IAC - 12 & $146,9^{1.2} \mathrm{a}$ & 81,0 a & 67,7 a & 85,7 \\
\hline & IAC -17 & $86,6 \quad b$ & 56,0 a & 55,5 a & 64,6 \\
\hline & IAC - 19 & $78,3 \quad b$ & 55,1 a & 53,5 a & 71,1 \\
\hline & \multicolumn{5}{|c|}{ DMS $=1,58 \quad C V=8,77 \%$} \\
\hline \multirow{4}{*}{ Tardia } & IAC - 12 & 147,7 & 85,3 & 49,9 & 89,9 a \\
\hline & IAC - 17 & 95,3 & 55,3 & 46,3 & $64,0 \quad b$ \\
\hline & IAC - 19 & 107,7 & 66,7 & 39,5 & $68,5 \mathrm{~b}$ \\
\hline & \multicolumn{4}{|c|}{ DMS $=0,96$} & \\
\hline \multirow{4}{*}{ Safrinha } & IAC -12 & 47,9 & 40,6 & 26,6 & 37,9 a \\
\hline & IAC -17 & 47,1 & 26,9 & 20,6 & 30,6 a \\
\hline & IAC - 19 & 58,0 & 34,2 & 28,3 & 39,2 a \\
\hline & \multicolumn{4}{|c|}{ DMS $=1,13$} & \\
\hline
\end{tabular}

${ }^{1}$ Médias seguidas por letras distintas, na coluna, diferem entre si pelo teste de Tukey a 0,05 de significância.

${ }^{2} \operatorname{Dados}(\mathrm{x})$ transformados em $\sqrt{x}$.

detectou diferenças altamente significativas para o fator cultivar, nas três épocas de semeadura, sendo que para densidade foi verificado efeito significativo apenas na época tardia de semeadura, não havendo efeito de interação cultivar $x$ densidade (Tabela 3).

Nas épocas de semeadura normal e safrinha, o cultivar IAC-12 produziu grãos mais leves que o IAC-17 e este, mais leve que o IAC-19. Na semeadura de época tardia, por sua vez, o IAC-17 diferiu significativamente dos outros dois cultivares, produzindo grãos mais pesados que o IAC-19 e este, com maior massa que o IAC-12. Na época de semeadura safrinha, o desempenho foi decrescente do IAC-19 para o IAC-17 e deste para o IAC-12. 
Tabela 9. Valores médios da massa de 1000 grãos observados nas épocas de semeadura normal, tardia e safrinha para os cultivares de soja IAC-12, IAC-17 e IAC-19, em três densidades de plantas.

\begin{tabular}{|c|c|c|c|c|c|}
\hline \multirow{2}{*}{ Épocas } & \multirow{2}{*}{ Cultivares } & \multicolumn{3}{|c|}{ Densidades (plantas $\mathrm{m}^{-1}$ ) } & \multirow{2}{*}{ Médias } \\
\hline & & 10 & 20 & 30 & \\
\hline \multirow{4}{*}{ Normal } & IAC - 12 & 148,0 & 148,9 & 146,4 & $147,8^{1} \quad \mathrm{c}$ \\
\hline & IAC - 17 & 167,0 & 166,6 & 166,8 & $166,8 \quad b$ \\
\hline & IAC - 19 & 176,0 & 183,7 & 179,8 & 179,9 a \\
\hline & \multicolumn{4}{|c|}{$\mathrm{DMS}=6,76$} & \\
\hline \multirow{4}{*}{ Tardia } & IAC - 12 & 118,8 & 124,7 & 120,5 & $121,3 \quad \mathrm{c}$ \\
\hline & IAC -17 & 151,8 & 163,4 & 167,4 & 160,9 a \\
\hline & IAC - 19 & 148,6 & 150,7 & 150,6 & $150,0 \quad b$ \\
\hline & \multicolumn{4}{|c|}{$\mathrm{DMS}=6,18$} & \\
\hline \multirow{3}{*}{ Safrinha } & IAC - 12 & 109,0 & 109,4 & 112,1 & 100,2 \\
\hline & IAC -17 & 127,7 & 125,8 & 120,5 & $124,7 \quad b$ \\
\hline & IAC - 19 & 138,7 & 142,1 & 140,7 & $140,5 \mathrm{a}$ \\
\hline
\end{tabular}

DMS $=4,71 \quad \mathrm{CV}=3,10 \%$

${ }^{1}$ Médias seguidas por letras distintas, na coluna, diferem entre si pelo teste de Tukey a 0,05 de significância.

Não houve efeito significativo de densidade nas épocas de seme adura normal e safrinha, indicando que as diferentes populações de plantas não influenciaram na massa de 1000 grãos. Na semeadura tardia, a análise de variância mostrou significância $(\mathrm{P}<0,05)$, com a análise de regressão polinomial indicando que as variações observadas para a massa de 1000 grãos independem do fator cultivar e são explicadas por regressão linear e demonstra que se aumentando a densidade de plantas na linha aumenta-se a massa de grãos produzidos (Tabela 12).

Valores médios do rendimento de grãos $\left(\mathrm{kg} \mathrm{ha}^{-1}\right)$ nas épocas de semeadura normal, tardia e safrinha para os cultivares de soja IAC - 12, IAC - 17 e IAC - 19, nas densidades de 10, 20 e 30 plantas $\mathrm{m}^{-1}$, são 
apresentados na Tabela 10. A análise da variância revelou valores de $F$ significativos para o fator cultivar com $\mathrm{P}<0,05$ na primeira época e $\mathrm{P}<$ 0,01 na época de semeadura safrinha. Na época de semeadura tardia o teste $\mathrm{F}$ não apresentou diferenças para este fator.

Com relação ao fator densidade, não se verificou efeito significativo nas três épocas, como também não se constatou significância para a interação cultivar $x$ densidade, demonstrando que a soja é capaz de compensar, aumentando a produção por planta, quando o estande apresentase abaixo do usualmente recomendado. A análise comparativa entre médias para o fator cultivar na primeira época de semeadura revelou que o cultivar IAC-12 foi mais produtivo que o IAC-17, porém não diferiu do IAC-19, sendo que o IAC-17 foi o único a produzir menos de $3000 \mathrm{~kg} \mathrm{ha}^{-1}$.

$\mathrm{Na}$ semeadura tardia os três cultivares apresentaram elevados valores para o rendimento de grãos, porém sem diferenças significativas entre si. Na época de semeadura safrinha, o cultivar IAC-19 foi significativamente superior aos demais, rendendo praticamente o dobro da quantidade de grãos produzida individualmente pelos cultivares IAC-12 e IAC17. Provavelmente, devido ao seu ciclo de maturação mais prolongado, $o$ cultivar IAC-19, apresentou-se melhor adaptado às condições ambientais proporcionadas pela semeadura em época safrinha.

Quanto ao fator densidade, apenas na terceira época de semeadura a análise de regressão polinomial revelou valores de $F$ significativos, onde as variaçộes em rendimento observadas para as diferentes densidades são independentes do fator cultivar e explicadas por regressão linear (Figura 1). Observa-se que, dentro do intervalo estudado, para cada unidade de planta aumentada na densidade por metro de linha, tem-se um acréscimo aproximado de $10 \mathrm{~kg}$ de grãos por hectare.

Como pode ser visto, nas épocas de semeadura normal e tardia verificaram-se os maiores rendimentos, onde os cultivares puderam, teoricamente, demonstrar todo o seu potencial produtivo, sem, contudo, diferirem significativamente, na época se semeadura tardia (onde se obteve os maiores rendimentos). Maiorés rendimentos também foram encontrados por Demuner (1988) para vários cultivares de soja, quando semeados em época considerada pelo autor como tardia (24/11), no Estado do 
Tabela 10. Valores médios do rendimento de grãos $\left(\mathrm{kg} \mathrm{ha}^{-1}\right)$ nas épocas de semeadura normal, tardia e safrinha para os cultivares de soja IAC - 12, IAC - 17 e IAC - 19, manejados sob três densidades de plantas.

\begin{tabular}{|c|c|c|c|c|c|}
\hline \multirow{2}{*}{ Épocas } & \multirow{2}{*}{ Cultivares } & \multicolumn{3}{|c|}{ Densidades (plantas $\mathrm{m}^{-1}$ ) } & \multirow{2}{*}{ Médias } \\
\hline & & 10 & 20 & 30 & \\
\hline \multirow{4}{*}{ Normal } & $\mathrm{IAC}-12$ & 3613,7 & 3548,9 & 2986,0 & $3382,9^{1}$ a \\
\hline & $\mathrm{IAC}-17$ & 2928,7 & 2701,4 & 2851,2 & $2827,1 \quad b$ \\
\hline & IAC - 19 & 3181,3 & 2951,2 & 3407,2 & $3180,0 \mathrm{ab}$ \\
\hline & DMS & $=494,44$ & \multicolumn{2}{|c|}{$\mathrm{CV}=12,98 \%$} & \\
\hline \multirow{4}{*}{ Tardia } & IAC -12 & 3049,9 & 3743,2 & 3703,5 & 3498,9 a \\
\hline & $\mathrm{IAC}-17$ & 2784,2 & 3646,8 & 2381,6 & 2937,5 a \\
\hline & IAC - 19 & 3508,5 & 3584,3 & 3407,8 & 3500,2 a \\
\hline & DMS & $=823,27$ & \multicolumn{2}{|c|}{$C V=20,43 \%$} & \\
\hline \multirow{4}{*}{ Safrinha } & $\mathrm{IAC}-12$ & 627,4 & 778,8 & 968,4 & $791,5 \quad b$ \\
\hline & $\mathrm{IAC}-17$ & 664,3 & 877,2 & 655,6 & $791,5 \quad b$ \\
\hline & IAC - 19 & 1360,3 & 1544,8 & 1623,8 & 1509,6 a \\
\hline & DMS & $=232,68$ & \multicolumn{2}{|c|}{$\mathrm{CV}=18,91 \%$} & \\
\hline
\end{tabular}

'Médias seguidas por letras distintas, na coluna, diferem entre si pelo teste de Tukey a 0,05 de significância

Mato Grosso do Sul. Para Peixoto (1999), essas diferenças mostram que é possível manejar cultivares de acordo com seu ciclo de maturação, visando obter-se ganhos em produtividade, para cada época.

Comparando-se os efeitos do atraso de épocas de semeadura sobre os cultivares, constatou-se que a superioridade das épocas de semeadura normal e tardia, em relação à safrinha, foi determinada pelas condições ambientais, durante as fases fenológicas dos cultivares, influenciando os componentes de produção da planta e comprometendo o rendimento final nessa época. Essas perdas no rendimento, devido ao atraso de época de semeadura também foram constatadas por Nakagawa et al. (1988), Bhéring (1989), Marcos Filho (1990), Embrapa (1996), Marchiori (1998) e Peixoto (1999). 


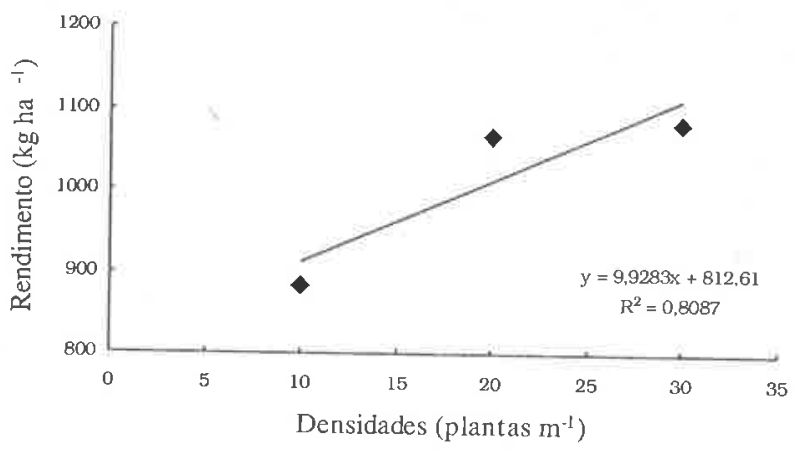

Figura 1. Variação no rendimento de grãos para os cultivares de soja IAC-12, IAC-17 e IAC-19, em função da densidade de plantas na linha em época de semeadura safrinha.

As perdas ocorridas entre as épocas, condicionadas pelas mudanças nessas características, conforme o cultivar utilizado, somaram 76\% para IAC-17 (precoce), 75\% para IAC-12 (semiprecoce) e 55\% para IAC19 (médio). Na época de semeadura safrinha, verifica-se o melhor desempenho do cultivar de ciclo de maturação médio (IAC-19), podendo ser uma opção para esta época de semeadura no Estado de São Paulo, principalmente visando à produção de sementes, mesmo em detrimento do rendimento de grãos, uma vez que as características bioclimáticas desta época favorecem a qualidade de sementes.

O melhor desempenho do cultivar IAC - 19 está de acordo com Embrapa (1996) ao afirmar que cultivares de ciclo de maturação médio a semitardio têm maiores potenciais de rendimento para semeaduras mais tardias, fato este, comprovado por Marchiori (1998) e Peixoto (1999).

A associação de precocidade de ciclo com juvenilidade longa, em um cultivar de soja como IAC-17, não garante a manutenção de alta produtividade e de boa altura de planta para a colheita em épocas de semeadura muito tardias, como no caso da época de safrinha, haja vista, ter sido o cultivar que apresentou, em média, o menor rendimento final de grãos. 
O conjunto dos resultados apresentados é, possivelmente, uma decorrência do equilíbrio entre os caracteres estudados e os componentes de produção da planta, devido aos efeitos de compensação entre eles. As estimativas de correlações simples (r) para todas as combinações das características estudadas são apresentadas na Tabela 11, onde são comparados a altura final de plantas (AFP), o número de nós (NN) e o número de ramificações (NR), o número total de vagens por planta (NTV), o número total de grãos por planta (NTG) e a massa de mil grãos (M1000) com o rendimento de grãos (REND $\left.\left(\mathrm{kg} \mathrm{ha}^{-1}\right)\right)$.

Tabela 11. Estimativa dos coeficientes de correlação simples ( $r$ ) entre algumas caraterísticas agronômicas com o rendimento de grãos de três cultivares de soja em três épocas de semeadura e três densidades de plantas.

\begin{tabular}{lc}
\hline \multicolumn{1}{c}{ Características Agronômicas } & Rendimento de grãos ( $\mathbf{r}$ ) \\
\hline Altura final de plantas (AFP) & $0,6463^{* *}$ \\
Número de nós final (NNF) & $0,6398^{* *}$ \\
Número de ramificaçōes (NR) & $0,3197^{* *}$ \\
Número total de vagens por planta (NTV) & $0,5672^{* *}$ \\
Número total de grãos por planta (NTG) & $0,5017^{* *}$ \\
Massa de 1000 grāos (Ml000) & $0,5313^{* *}$ \\
\hline
\end{tabular}

As características agronômicas AFP e NN estão correlacionadas significativa e positivamente com o rendimento de grãos, discordindo de resultados de Garcia (1992), onde a AFP e outros caracteres relacionados com o porte da planta não apresentaram importância na predição do rendimento. Entretanto, concordam com os resultados encontrados por Marchiori et al. (1999), que, independente da época de semeadura, verificaram que quanto maior a densidade de plantas de soja na linha, maior a altura final das plantas, menor o diâmetro da haste principal e menor o número de ramificações por planta. O número de ramificações, apesar de altamente significativo e positivo, apresentou correlação muito baixa. 
Sendo o rendimento final dependente da interação entre os componentes da produção da planta, os resultados apresentados mostram que pelo menos $50 \%$ do rendimento em grãos está correlacionado positiva e significativamente com número total de vagens, número total de grãos e massa de 1000 grãos (Tabela 11). Entretanto, para Garcia (1979), apenas o número total de grãos apresentou correlação significativa, sendo que o número total de vagens não assegurou ser um bom indicador do rendimento.

\section{CONCLUSÕES}

a) Os caracteres agronômicos e os componentes de produção da planta apresentam variações entre si, com efeito de compensação, no sentido de uniformizar o rendimento de grãos, entre cultivares, densidades e época de semeadura;

b) Em época de semeadura safrinha, o cultivar IAC-19 apresenta melhor desempenho para rendimento de grãos;

c) Independentemente da densidade de plantas, a época de semeadura é a variável que mais influencia nas características agronômicas e no rendimento de grãos.

\section{REFERÊNCIAS BIBLIOGRÁFICAS}

BHÉRING, M.C., 1989. Influência de Épocas de Plantio sobre algumas Características Agronômicas e Qualidade das Sementes de Soja (Glycine max (L.) Merrill). Viçosa, 57p. Dissertação de Mestrado Universidade Federal de Viçosa.

CÂMARA, G.M.S., 1991. Efeito do Fotoperíodo e da Temperatura no Crescimento, Florescimento e Maturação de Cultivares de Soja (Glycine max (L.) Merrill). Viçosa, 1991. 266p. Tese de Doutorado - Universidade Federal de Viçosa.

CÂMARA, G.M.S., 1998. Desempenho Produtivo dos Cultivares de Soja IAC-12, IAC-17 e IAC-19 em Três Épocas de Semeadura e Cinco Densidades de Plantas. Piracicaba, 165p. Tese de Livre Docente - Escola Superior de Agricultura Luiz de Queiroz, Universidade de São Paulo. 


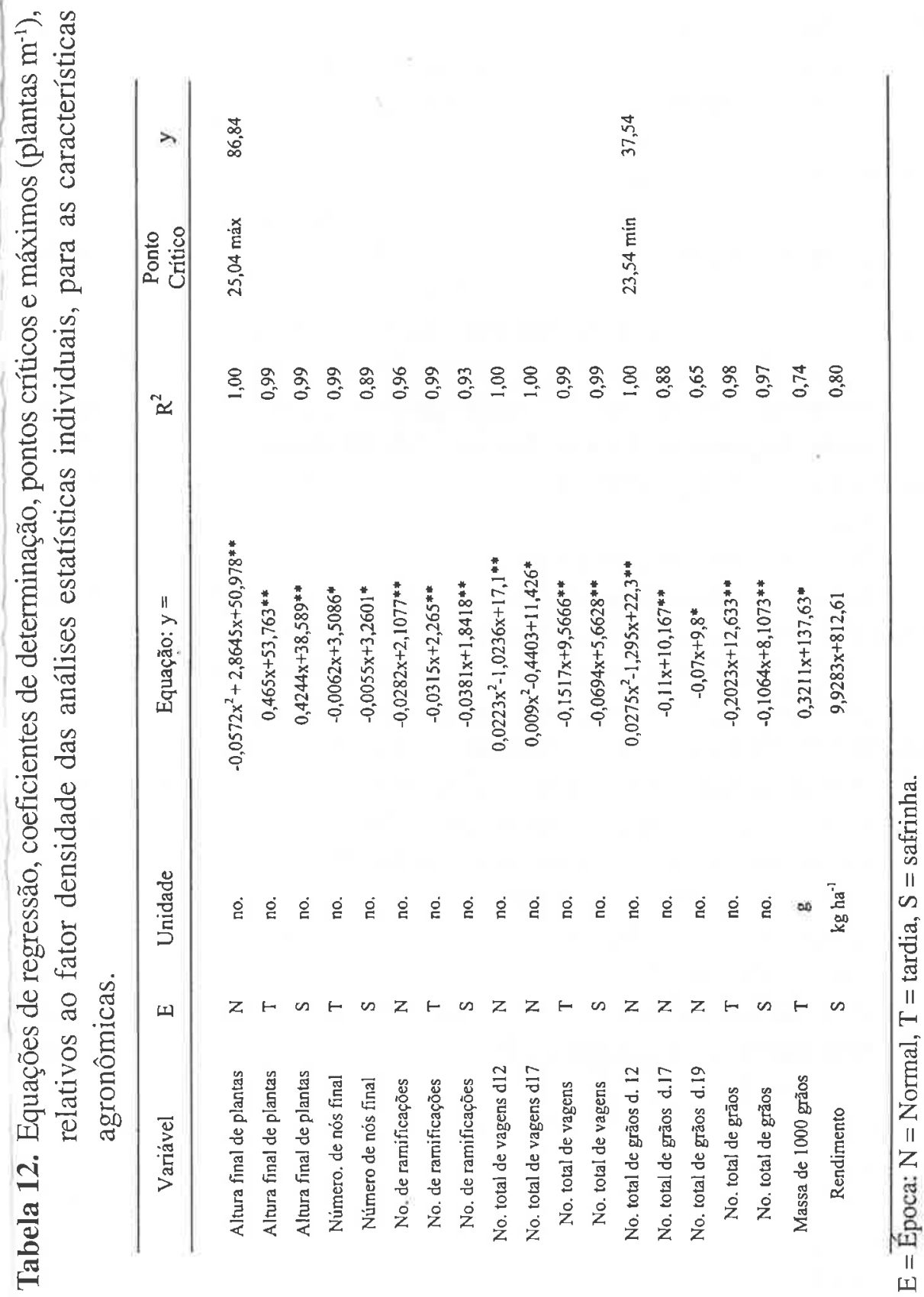


DEMUNER, A.M., 1988. Influência da Época de Semeadura, Espaçamento e População de Plantas, em Regime de Irrigação Suplementar ou de Sequeiro, sobre a Cultura da Soja. Viçosa,. 65p. Tese de Doutorado - Universidade Federal de Viçosa.

EMPRESA BRASILEIRA DE PESQUISA AGROPECUÁRIA. Centro

Nacional de Pesquisa de Soja, 1996. Recomendações Técnicas para a Cultura da Soja na Região Central do Brasil 1996/97. Londrina, 149p. (Embrapa/CNPSo. Documentos, 88).

GAUDÊNCIO, C.A.A.; GAZZIERO, D.L.P.; JASTER, F.; GARCIA, A.; WOBETO, C., 1990. População de Plantas de Soja no Sistema de

Semeadura Direta para o Centro-Sul do Estado do Paraná. Comunicado Técnico do Centro Nacional de Pesquisa de Soja, 47:1-4.

MARCHIORI, L.F.S., 1998. Desempenho Vegetativo e Produtivo de Três

Cultivares de Soja em Cinco Densidades Populacionais nas Épocas Normal e Safrinha. Piracicaba, 55p. Dissertação de Mestrado - Escola

Superior de Agricultura Luiz de Queiroz, Universidade de São Paulo. MARCHIORI, L.F.S.; CÂMARA, G.M.S.; PEIXOTO, C.P.; MARTINS, M.C., 1999. Desempenho Vegetativo de Cultivares de Soja em Épocas Normal e Safrinha. Sci. Agric., 56(2):383-390.

MARCOS FILHO, J.; NOVEMBRE, A.D.L.C., 1990. Características Agronômicas e Fenologia da Soja (Glycine max (L.) Merrill) sob Influência da Época de Semeadura. Piracicaba: ESALQ, 57p. (Relatório técnico apresentado ao Conselho de Desenvolvimento Científico e Tecnológico - CNPq).

MASCARENHAS, H.A.A.; TANAKA, R.T., 1996. Soja. In: RAIJ, B van; CANTARELLA, H.; QUAGGIO, J. A.; FURLANI, A. M. C. (Ed.) Recomendações de Adubação e Calagem para o Estado de São Paulo. 2.ed. Campinas: Instituto Agronômico, p.202-203. (IAC. Boletim Técnico, 100).

NAKAGAWA, J.; ROSOLEM, C.A.; MACHADO, J.R., 1988. Efeito da

Densidade de Plantas no Comportamento de Cultivares de Soja, em

Duas Épocas de Semeadura. Pesq. Agrop. Brasil., 23(9):1003-1014. OMETTO, J.C. Bioclimatologia Vegetal. São Paulo: Agronômica Ceres, 1981. 440p. 
PEREIRA, A.R.; VILLA NOVA, N.A.; SEDIYAMA, G.C., 1997. Evapo(Transpi)ração. Piracicaba: FEALQ, 183p.

PEIXOTO, C.P., 1999. Análise de Crescimento e Rendimento de Três Cultivares de Soja em Três Épocas de Semeadura e Três Densidades de Plantas. Piracicaba. 151p. Tese de Doutorado - Escola Superior de Agricultura Luiz de Queiroz, Universidade de São Paulo.

QUEIROZ, E. F., 1975. Efeito de Época de Plantio e População sobre o Rendimento e outras Características Agronômicas de Quatro Cultivares de Soja. Porto Alegre. 109p. Dissertação de Mestrado - Faculdade de Agronomia, Universidade Federal do Rio Grande do Sul. ROCHA, V.S.; OLIVEIRA, A.B.; SEDIYAMA, T.; GOMES, J.L.L.; SEDIYAMA, C.S.; PEREIRA, M.G., 1984. A Qualidade da Semente de Soja. Viçosa: Universidade Federal de Viçosa. 76p. (UFV. Boletim, 188).

SEDIYAMA, T., 1991. Melhoramento de Soja (Glycine max (L.) Merrill) na Universidade Federal de Viçosa. In: SIMPÓSIO SOBRE CULTURA E PRODUTIVIDADE DA SOJA, 1., Piracicaba, 1991. Anais. Piracicaba.

TOLEDO, J.F.F.; ALMEIDA, L.A.; KIIHL, R.A.S.; CARRÃO-PANIZZI, M.C.; KASTER, M.; MIRANDA, L.C.; MENOSSO, O.G., 1994. Genetics and Breeding. In: BRAZILIAN AGRICULTURAL RESEARCH ENTERPRISE. National Soybean Research Center. Tropical Soybean: Improvement and Production. Rome: FAO, 1994. p.19-36 (Plant Production and Protection Series, 27). 